\title{
Small Alcohols Revisited: CCSD(T) Relative Potential Energies for the Minima, First- and Second-Order Saddle Points, and Torsion-Coupled Surfaces
}

\author{
Karl N. Kirschner, ${ }^{\dagger},+, \S \odot$ Wolfgang Heiden, ${ }^{\dagger, \S}$ and Dirk Reith ${ }^{\ddagger, \S}$ \\ ${ }^{\dagger}$ Department of Computer Science, ${ }^{\star}$ Department of Electrical Engineering, Mechanical Engineering and Technical Journalism, and \\ ${ }^{\S}$ Institute of Visual Computing, Bonn-Rhein-Sieg University of Applied Sciences, Grantham-Allee 20, 53757 Sankt Augustin, \\ Germany
}

\section{Supporting Information}

ABSTRACT: The elucidation of conformations and relative potential energies (rPEs) of small molecules has a long history across a diverse range of fields. Periodically, it is helpful to revisit what conformations have been investigated and to provide a consistent theoretical framework for which clear comparisons can be made. In this paper, we compute the minima, first- and second-order saddle points, and torsioncoupled surfaces for methanol, ethanol, propan-2-ol, and propanol using consistent high-level MP2 and $\operatorname{CCSD}(\mathrm{T})$ methods. While for certain molecules more rigorous methods were employed, the $\operatorname{CCSD}(\mathrm{T}) /$ aug-cc-pVTZ//MP2/aug-ccpV5Z theory level was used throughout to provide relative energies of all minima and first-order saddle points. The rPE

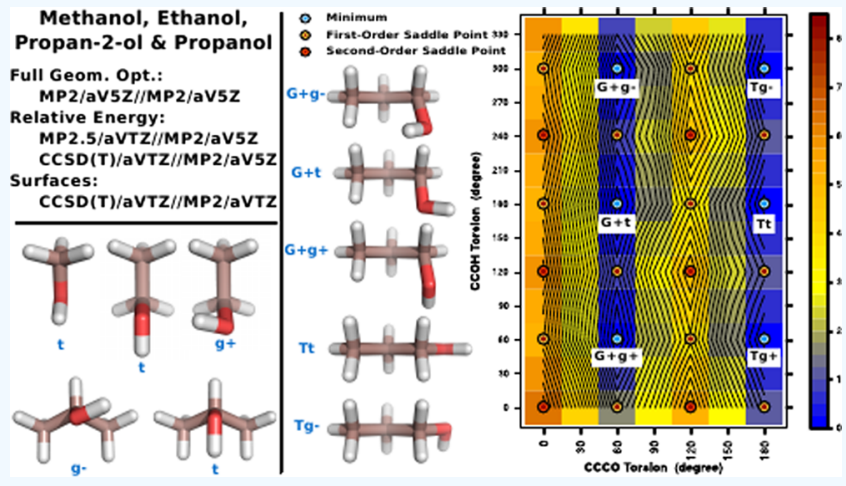
surfaces were uniformly computed at the $\operatorname{CCSD}(\mathrm{T}) /$ aug-ccpVTZ//MP2/aug-cc-pVTZ level. To the best of our knowledge, this represents the most extensive study for alcohols of this kind, revealing some new aspects. Especially for propanol, we report several new conformations that were previously not investigated. Moreover, two metrics are included in our analysis that quantify how the selected surfaces are similar to one another and hence improve our understanding of the relationship between these alcohols.

\section{INTRODUCTION}

Understanding the conformational space of molecules and their underlying relative potential energy ( $\mathrm{rPE}$ ) surfaces are important goals in scientific disciplines whose experimental observables can be explained at a molecular level. Sophisticated quantum mechanics theories have proven to be a powerful tool in providing the structures and relative energies of minima that are as accurate as those provided by experimental spectroscopy. ${ }^{1-4}$ An advantage that quantum mechanics has over experimental methods is its relative ease in characterizing first- and secondorder saddle points and to elucidate the three-dimensional rPE surfaces generated by coupling two internal coordinates (e.g., two torsion angles). This is especially important if energy barriers are comparably low between minima. However, due to their computational cost, studies that employ theory levels capable of reproducing experimental data generally limit themselves to small molecules and to their stationary points. Nevertheless, the information drawn from small molecules can be very helpful and generalized in some respects.

In this paper we present the minima, first- and second-order saddle points, and torsion-coupled rPE surfaces of the four smallest alcohol molecules-methanol, ethanol, propan-2-ol, and propanol-computed at the $\operatorname{CCSD}(\mathrm{T}) /$ aug-cc-pVTZ// $\mathrm{MP2} /$ aug-cc-pVnZ $(\mathrm{n}=\mathrm{T}$ or 5$)$ theory level. Our motivation for this study is to (1) provide a comprehensive comparison of the minima and first-order saddle points using a single rigorous theory level, (2) better understand the qualitative and quantitative nature of the rPE surfaces formed by the coupling between two torsion angles, and (3) determine the degree of similarity between comparable surfaces. The results presented herein, and in particular those associated with propanol, could be used by experimentalists in their data interpretation. Theoreticians developing force fields could use the results as target benchmark data in parameter optimization or in the development of new functional forms.

\section{RESULTS}

The MP2/aV5Z structures for all minima and first-order saddle points are presented in Figures 1, 2, and Supporting Information Figure 1, as well as in xyz-formatted files in the Supporting Information material. The values of the selected internal coordinates are given in Supporting Information Tables 1-4, as optimized at HF/6-31G(d), MP2/VTZ, MP2/aVTZ, MP2/

Received: September 14, 2017

Accepted: November 22, 2017

Published: January 16, 2018 

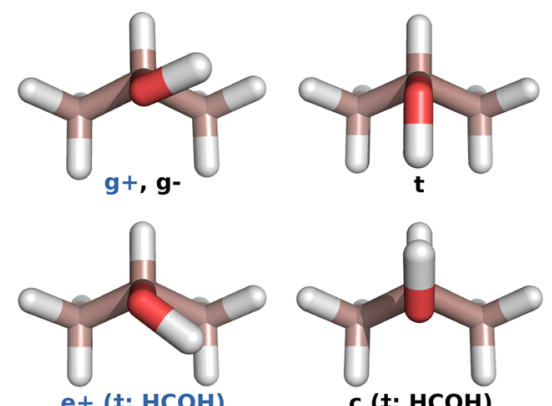

c (\$: $\mathrm{HCOH})$
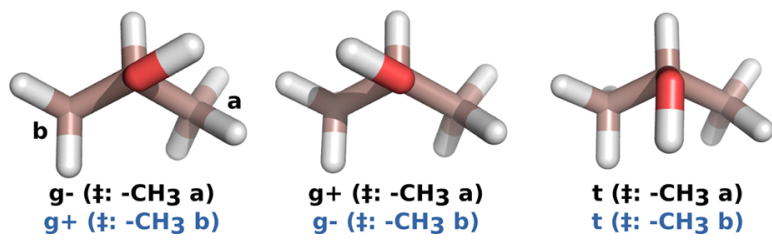

Figure 1. MP2/aV5Z fully optimized structures and conformational nomenclature (see Methodology) for propan-2-ol's minima and firstorder saddle points. The black labels are for the structures shown, whereas the isomer labels are given in blue.

VQZ, MP2/aVQZ, and MP2/aV5Z theory levels and include experimental values when available. Table 1 provides the rotational constants determined using MP2/aVTZ (i.e., the theory at which vibrational analyses were performed), coupled cluster, and experimental microwave geometries. The corresponding root-mean-square deviations (RMSDs) for each fully optimized conformation with respect to MP2/aV5Z geometries are given in Supporting Information Table 5 and are summarized in Table 2.

The rPE of each fully optimized stationary point with respect to a molecule's global minimum are given in Tables 3-6. These energies were computed at HF, MP2, MP2.5, and $\operatorname{CCSD}(\mathrm{T})$ theory levels and include notable theoretical and experimental values from literature. The average absolute error of each $\mathrm{rPE}$ with respect to the most rigorous theory employed for a given molecule is also provided for ease of comparison in Table 7. Supporting Information Table 6 provides additional rPEs for propanol computed at MP2.5/aVTZ//MP2/aVTZ and CCSD(T)/aVTZ//MP2/aVTZ theory levels.

The CCSD $(\mathrm{T}) \mathrm{rPE}$ surfaces formed by the coupling of two torsion angles within ethanol, propanol, and propan-2-ol are shown in Figures 3-5, and Supporting Information Figure 2. The corresponding rPEs that generated these figures are given in Supporting Information Tables 7-13. For ethanol, the rPEs along the motion of single torsion angles, relative to their local minimum, are given in Supporting Information Figures 3 and 4, with corresponding values in Supporting Information Tables 14 and 15. For propanol's surfaces, all of the rPEs were determined by identifying the lowest energy across all surfaces generated. That is opposed to the rPEs using the minima within each surface, which would disallow direct quantitative comparisons to be made between them.

To quantify the overall "repulsiveness" of an rPE surface involving methyl rotation, an average of the rPEs for each surface was computed. The average $\operatorname{CCSD}(\mathrm{T}) \mathrm{rPE}$ of the surfaces that are defined by the coupling of the methyl and hydroxyl rotations (i.e., Figures 3, 5, and Supporting Information Figure 2) is given in Table 8. Differences between the resulting averaged rPE are also provided as a metric for evaluating if one surface is generally

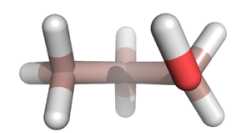

$\mathrm{Cg}+(\ddagger \mathrm{CCCO})$ Cg- (\$: CCCO)

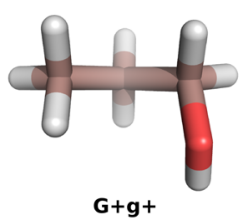

G-g-

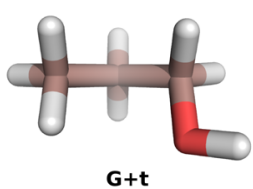

$\mathbf{G}+\mathbf{t}$

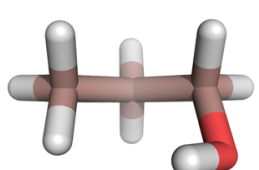

G+g-
G-g+

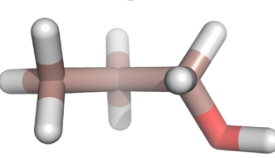

$E+t$ (‡: CCCO) E-t (†: CCCO)

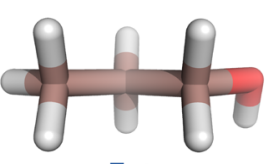

Tg+
Tg-

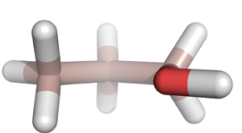

Ct (\$: Ccco)

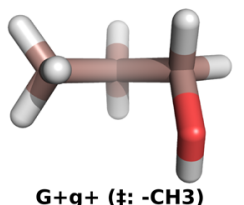

G-g- (\$: - CH3)

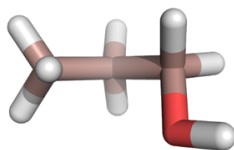

G+t (\$: - CH3) G-t (¥:-CH3)
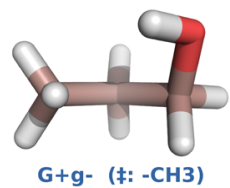
G-g+ (\$: - CH3)

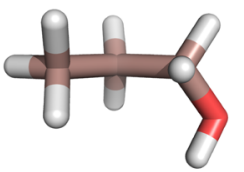

E+g- (\$: CCCO) $\mathrm{E}-\mathrm{g}+(\ddagger: \mathrm{CCCO})$

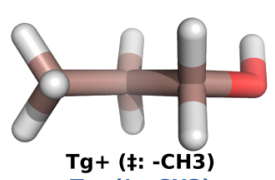
Tg+ (\$: -CH3)
Tg- (¥: - CH3)

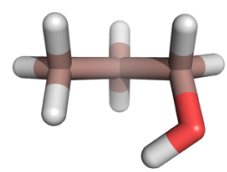

$\mathbf{G}+\mathbf{c}(\neq: \mathbf{C C O H})$ G-c (‡: CCOH)

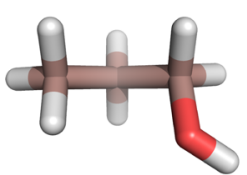

$\mathbf{G}+\mathbf{e}+($ (: $\mathbf{C C O H})$ G-e- ( $\ddagger$ : $\mathrm{COH})$

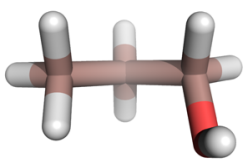

G+e- (‡: $\mathbf{C C O H})$ $\mathrm{G}-\mathrm{e}+(\ddagger \mathrm{CCOH})$

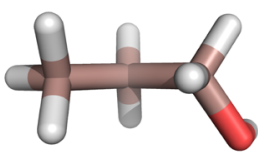

$\mathrm{E}+\mathrm{g}+(\ddagger \mathbf{C C C O})$ E-g- (\#: CCCO)
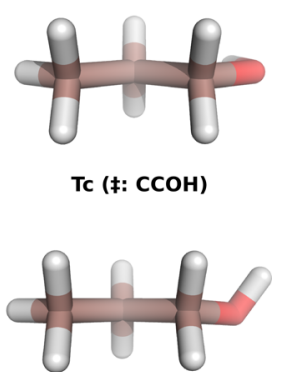

$\mathrm{Te}+(\$: \mathrm{CCOH})$ Te- (‡: CCOH)
Tc (‡: CCOH)

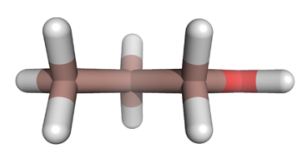

Tt

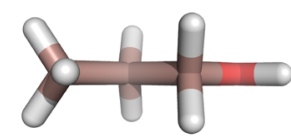

Tt (\$: - $\mathrm{CH} 3)$
Figure 2. MP2/aV5Z fully optimized structures and nomenclature for propanol's minima and first-order saddle points. See Figure 1 for the explanation of the labels' colors.

more repulsive or stable than another surface. Table 8 also gives the similarity between two surfaces as determined by computing their similarity index using the following equation ${ }^{15,16}$

$$
\mathrm{SI}=\frac{\sum_{i=1}^{m} u_{i}^{\mathrm{a}} u_{i}^{\mathrm{b}}}{\max \left(\sum_{i=1}^{m} u_{i}^{\mathrm{a}^{2}}, \sum_{i=1}^{m} u_{i}^{\mathrm{b}^{2}}\right)}
$$

where $u_{i}^{\mathrm{a}}$ and $u_{i}^{\mathrm{b}}$ are the values of the $\mathrm{rPE}$ on surfaces a and $\mathrm{b}, i$ specifies a specific point defined by the internal coordinates [i.e., $(\phi, \psi)]$, and $m$ is the total number of rPEs on each surface. The closer the index is to +1 , the more similar are the two rPE surfaces being compared.

\section{DISCUSSION}

Choosing the Theory Level for Computing Surfaces. Because of the number of calculations needed to compute the rPE surfaces herein, the first task was to identify the theory to be used in the two-torsion constraint optimizations. To this end, full 
Table 1. Rotational Constants $\left(\mathrm{cm}^{-1}\right)$ Computed Using MP2/ aVTZ and Coupled Cluster Geometries, with Average Experimental Values Also Provided ${ }^{a}$

\begin{tabular}{|c|c|c|c|}
\hline methanol & MP2/aVTZ & $\operatorname{CCSD}(\mathrm{T}) / \mathrm{aVQZ}^{b}$ & experimental average \\
\hline A & $4.290(+0.033)$ & $4.305(+0.048)$ & $4.25732^{c}$ \\
\hline B & $0.826(+0.002)$ & $0.831(+0.007)$ & $0.82351^{c}$ \\
\hline $\mathrm{C}$ & $0.797(+0.004)$ & $0.802(+0.009)$ & $0.79260^{c}$ \\
\hline ethanol & MP2/aVTZ & $\mathrm{CCSD} / \mathrm{aVTZ}^{b}$ & experimental average \\
\hline \multicolumn{4}{|c|}{$\mathbf{t}$} \\
\hline A & $1.170(+0.006)$ & $1.185(+0.021)$ & $1.16386^{d}$ \\
\hline B & $0.315(+0.003)$ & $0.316(+0.004)$ & $0.31190^{d}$ \\
\hline $\mathrm{C}$ & $0.274(+0.002)$ & $0.275(+0.004)$ & $0.27136^{d}$ \\
\hline \multicolumn{4}{|c|}{ g } \\
\hline A & $1.149(+0.002)$ & & $1.14723^{d}$ \\
\hline B & $0.308(+0.000)$ & & $0.30819^{d}$ \\
\hline C & $0.272(+0.001)$ & & $0.27063^{d}$ \\
\hline propan-2-ol & $\mathrm{MP2} / \mathrm{aVTZ}$ & $\mathrm{CCSD} / \mathrm{aVTZ}{ }^{b}$ & experimental average \\
\hline \multicolumn{4}{|c|}{$\mathbf{t}$} \\
\hline A & $0.284(+0.001)$ & $0.292(+0.009)$ & $0.28316^{e}$ \\
\hline B & $0.271(+0.003)$ & $0.273(+0.005)$ & $0.26824^{e}$ \\
\hline $\mathrm{C}$ & $0.160(+0.001)$ & $0.161(+0.002)$ & $0.15895^{e}$ \\
\hline \multicolumn{4}{|c|}{ g } \\
\hline A & $0.290(+0.002)$ & & $0.28770^{e}$ \\
\hline B & $0.272(+0.003)$ & & $0.26848^{e}$ \\
\hline $\mathrm{C}$ & $0.160(+0.002)$ & & $0.15869^{e}$ \\
\hline propanol & MP2/aVTZ & $\mathrm{CCSD} / \mathrm{aVTZ}{ }^{b}$ & experimental average \\
\hline \multicolumn{4}{|c|}{ t } \\
\hline A & $0.889(+0.008)$ & $0.897(+0.016)$ & $0.88066^{f}$ \\
\hline B & $0.128(+0.001)$ & $0.128(+0.001)$ & $0.12683^{f}$ \\
\hline $\mathrm{C}$ & $0.119(+0.001)$ & $0.120(+0.002)$ & $0.11840^{f}$ \\
\hline \multicolumn{4}{|c|}{ g } \\
\hline A & $0.479(+0.001)$ & & $0.47802^{f}$ \\
\hline B & $0.174(+0.003)$ & & $0.17077^{f}$ \\
\hline $\mathrm{C}$ & $0.146(+0.002)$ & & $0.14424^{f}$ \\
\hline avg \% error & 0.75 & 1.50 & \\
\hline
\end{tabular}

${ }^{a_{T}}$ The error of the theoretical to experimental values are given in parentheses. The average percent error is also provided as a summary statistic. ${ }^{b}$ All coupled cluster calculations were performed with full electron correlations, whose values were obtained from ref 5 . These calculations represent the most rigorous theory that rotational constants were determined in the literature. ${ }^{c}$ References 6 and 7 . ${ }^{d}$ References 8 and $9 .{ }^{e}$ References $10-12 .{ }^{f}$ References 13 and 14 .

optimizations were performed using the following theory levels: HF/6-31G(d), MP2/VTZ, MP2/aVTZ, MP2/VQZ, MP2/ aVQZ, and MP2/aV5Z. For target values, experimental geometries are only available for methanol $(t)^{20,32-37}$ and ethanol $(t),{ }^{8,24,38}$ whereas coupled cluster geometries are available for methanol $(\mathrm{t})$, ethanol $(\mathrm{t})$, propan-2-ol $(\mathrm{g}-)$, and propanol $(\mathrm{Tt})$ (see Supporting Information Tables 1 and 2). ${ }^{5,39}$ First, let us consider the performance of MP2/aV5Z.

On average, MP2/aV5Z underestimates the experimental bond lengths and angles-with respect to experimental data averages-of methanol and ethanol by $0.006 \AA$ and $0.15^{\circ}$. In comparison to the best coupled cluster data, MP2/aV5Z on average overestimates bond lengths by $0.002 \AA$, underestimates angles by $0.15^{\circ}$, and underestimates torsions by $0.8^{\circ}$. In addition to internal coordinates, one can also compare rotational constants for gauging accuracy. Because MP2/aVTZ was the most rigorous theory level used for frequency analyses, its resulting rotational constants can be compared to experimental microwave values. As seen in Table 1, the theoretical rotational constants agree very well with experimental values, with an average percent error of $0.75 \%$. In fact, this theory level outperforms values determined using coupled cluster theory with large basis sets, which resulted on average in twice as much error (i.e., $1.50 \%$ ). Unfortunately, computing rotational constants through an MP2/aV5Z vibrational analysis was impossible using our available resources. Consequently, we make the assumption that increasing the basis size to aV5Z will not significantly alter the resulting optimized geometries, which is supported by the below paragraph. Because MP2/aV5Z is also the most robust (i.e., the best representation of orbital space) theory used for fully optimized conformations investigated herein, we subsequently used its structures as our benchmark targets.

Although tempting because of its low computational cost, HF/ 6-31G(d) clearly performs the worst at reproducing MP2/aV5Z geometries with an overall average RMSD of $0.019 \AA$ (Table 2). The MP2 optimizations using the Dunning-style basis sets increasingly showed convergence toward the $\mathrm{MP} 2 / \mathrm{aV} 5 \mathrm{Z}$ geometries, as expected. Ultimately, the MP2/aVTZ theory was chosen for generating the rPE surfaces since it consistently gave RMSD values close to $0.004 \AA$. MP2/VTZ was not chosen, even though it had favorable average RMSDs of 0.004-0.006 across all molecules because individual stationary points had RMSD values up to $0.015 \AA$ (e.g., propanol's $\mathrm{G}+\mathrm{g}+\left(\ddagger\right.$ : $\left.-\mathrm{CH}_{3}\right)$ in Supporting Information Table 5). The VQZ, aVQZ, and aV5Z basis sets were deemed too expensive for the slight improvements made in their RMSD values. The choice of MP2/aVTZ for constraint optimizations is further supported by the fact that propanol's $\operatorname{CCSD}(\mathrm{T}) / \mathrm{aVTZ} / / \mathrm{MP} 2 / \mathrm{aVTZ}$ and $\operatorname{CCSD}(\mathrm{T}) /$ aVTZ//MP2/aV5Z rPEs are equivalent to within $0.002 \mathrm{kcal}$ $\mathrm{mol}^{-1}$ (see Supporting Information Table 6).

MP2.5 Performance. In our previous study of octane and smaller unbranched hydrocarbons, ${ }^{30}$ dispersion forces were a

Table 2. Average All-Atom RMSD (̊̊) Computed Using All Minima and First-Order Saddle Points Investigated, Whose Geometries Were Fully Optimized at the Indicated Theory Levels ${ }^{a}$

\begin{tabular}{|c|c|c|c|c|c|c|c|}
\hline & \multirow[b]{2}{*}{ methanol } & \multirow[b]{2}{*}{ ethanol } & \multirow[b]{2}{*}{ propan-2-ol } & \multirow[b]{2}{*}{ propanol } & \multicolumn{3}{|c|}{ over all molecules } \\
\hline & & & & & $\max$ & $\min$. & average \\
\hline $\mathrm{HF} / 6-31 \mathrm{G}(\mathrm{d})$ & 0.009 & 0.013 & 0.019 & 0.022 & 0.040 & 0.008 & 0.019 \\
\hline MP2/VTZ & 0.005 & 0.004 & 0.005 & 0.006 & 0.015 & 0.003 & 0.005 \\
\hline MP2/aVTZ & 0.003 & 0.003 & 0.004 & 0.004 & 0.004 & 0.003 & 0.004 \\
\hline MP2/VQZ & 0.002 & 0.002 & 0.001 & 0.002 & 0.004 & 0.001 & 0.002 \\
\hline MP2/aVQZ & 0.001 & 0.001 & 0.001 & 0.001 & 0.001 & 0.001 & 0.001 \\
\hline \# of conformations & 2 & 6 & 7 & 20 & & 35 & \\
\hline
\end{tabular}

${ }^{a_{T}}$ The MP2/aV5Z geometries were used as reference structures. The overall maximum, minimum, and average RMSD for each theory level are also given. 


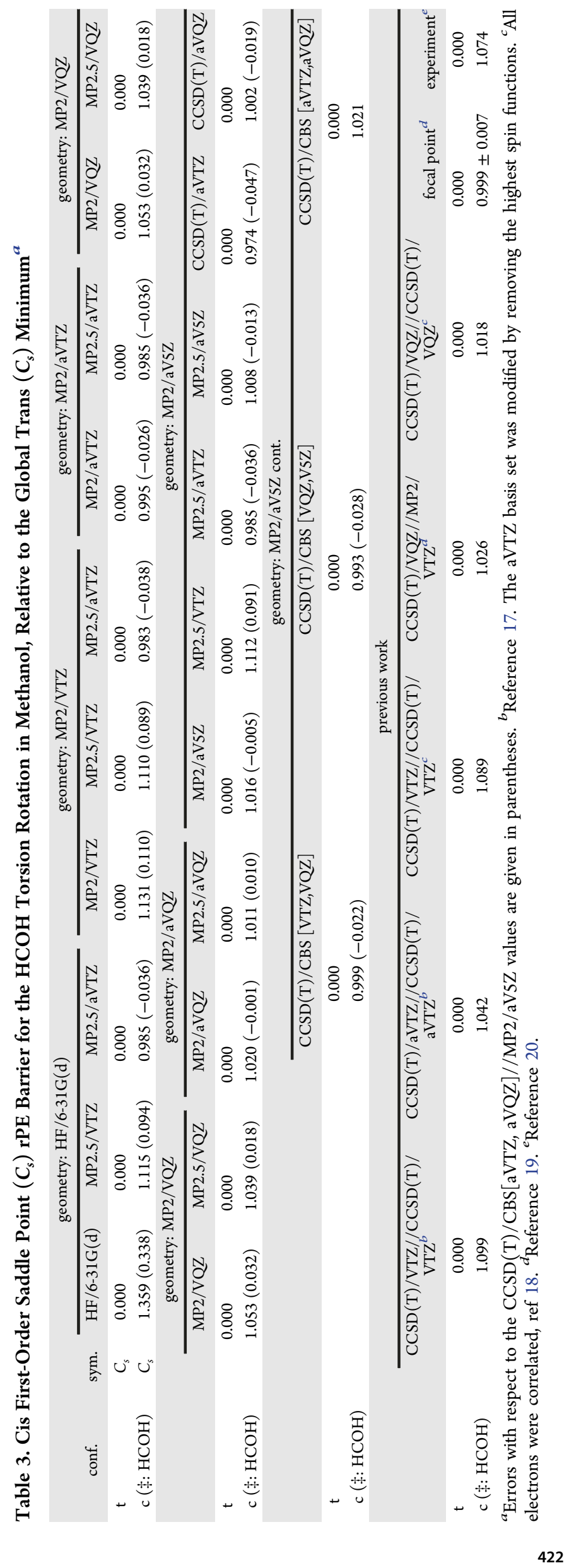




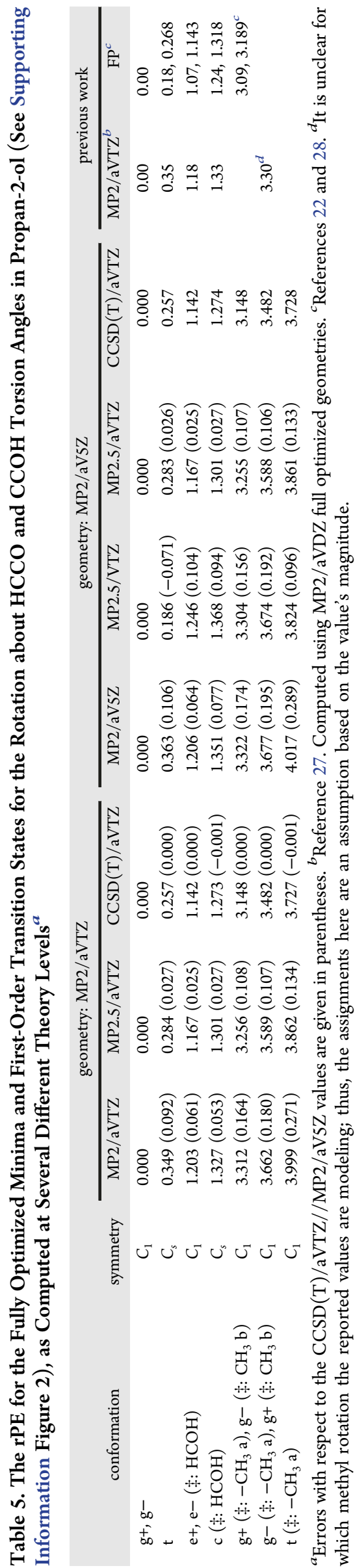

significant component to conformational rPEs. In that study, we found that MP2.5/aVTZ provided an rPE comparable to the more expensive CCSD $(\mathrm{T}) / \mathrm{aVTZ}$ and outperforms MP2 (see Table 7). Extending that comparison, the performance of MP2.5 was evaluated for small alcohols, whose conformational stability is dependent upon forces greater than dispersion. On average, the MP2.5/aVTZ rPEs are very close to those determined by $\operatorname{CCSD}(\mathrm{T})$ theory that employs triple zeta or larger basis sets on well-optimized geometries (Table 7). Computing the average absolute error over all fully optimized conformations listed in Tables 3-6 (i.e., 31 conformations, excluding the global minima) with respect to the best $\operatorname{CCSD}(\mathrm{T})$ theory computed, yields a value of $0.080 \mathrm{kcal} \cdot \mathrm{mol}^{-1}$ for MP2.5/aVTZ. Interestingly, computing the MP2.5/VTZ rPE results in an average absolute error of $0.134 \mathrm{kcal} \cdot \mathrm{mol}^{-1}$. This shows the importance of including augmented basis functions into the energy calculations.

For comparison to MP2, the average absolute error for MP2/ aV5Z is $0.164 \mathrm{kcal} \cdot \mathrm{mol}^{-1}$. Thus, for small alcohols on average, $\mathrm{MP2.5} / \mathrm{aVTZ}$ provides $\mathrm{rPEs}$ that are closer to $\mathrm{CCSD}(\mathrm{T})$ values than MP2 calculations alone. However, the performance of MP2.5 is dependent upon the individual conformations, as seen for a wide variety of propanol's conformations (Table 6). For example, the rPE for the $\mathrm{Cg}+(\ddagger$ : CCCO) conformation becomes significantly worse when computed using aVTZ (i.e., $0.236 \mathrm{kcal} \cdot \mathrm{mol}^{-1}$ ) versus the smaller VTZ (i.e., $0.040 \mathrm{kcal} \cdot \mathrm{mol}^{-1}$ ) basis set.

Specific Aspects for the Examined Molecules. Methanol. Being overall one of the smallest molecules, methanol has been well-studied by theoretical approaches. The hydroxyl rotation barrier has been established to be between 0.999 and $1.099 \mathrm{kcal} \cdot \mathrm{mol}^{-1}$ using $\operatorname{CCSD}(\mathrm{T})$ and focal point calculations (Table 3), ${ }^{17-19}$ which compares well with the experimental value of $1.07 \mathrm{kcal} \cdot \mathrm{mol}^{-1}{ }^{20}$ To the existing computational data, we contribute MP2.5 and CCSD(T)/CBS energies (Table 3). The best $\operatorname{CCSD}(\mathrm{T}) / \mathrm{CBS}$ barrier height was extrapolated using the data obtained from the aVTZ and aVQZ basis sets-resulting in a barrier of $1.021 \mathrm{kcal} \cdot \mathrm{mol}^{-1}$, which agrees well with the experimental value. With respect to the CCSD $(\mathrm{T}) / \mathrm{CBS}[\mathrm{aVTZ}$, aVQZ] results, the MP2.5 barrier heights that were computed using nonaugmented basis sets (i.e., VTZ and VQZ) were consistently overestimated (i.e., rPE range of $1.039-1.115 \mathrm{kcal}$. $\mathrm{mol}^{-1}$ ), whereas those computed using augmented basis sets (i.e., aVTZ, aVQZ, and aV5Z) underestimated the barrier (i.e., rPE range of $0.983-1.011 \mathrm{kcal} \cdot \mathrm{mol}^{-1}$ ).

Ethanol. Ethanol also has a long history of being investigated by both experimental and theoretical means. It has three minima [i.e., $(+/-)$-gauche, trans] and three first-order saddle points [i.e., $(+/-)$-eclipse, cis] about the $\mathrm{CCOH}$ torsion rotation (Supporting Information Figure 3). Previously, the most accurate results for ethanol's stationary points were computed by $\operatorname{CCSD}(\mathrm{T}) / \mathrm{aVTZ} / / \mathrm{MP} 2 / \mathrm{aVTZ},{ }^{21}$ and involved four of the possible six stationary points. The trans conformation was predicted to be $0.124 \mathrm{kcal} \cdot \mathrm{mol}^{-1}$ more stable than the $(+/-)$-gauche conformations, slightly overestimating the experimental values that range from 0.118 to $0.120 \mathrm{kcal}$. $\mathrm{mol}^{-1}$., 23 Concerning the hydroxyl rotational barrier, the $(+/-)$-eclipse and cis conformations were predicted to be 0.939 and $1.211 \mathrm{kcal} \cdot \mathrm{mol}^{-1}$ relative to the trans conformation, which are comparable to the experimental values of 1.15 and 1.26 $\mathrm{kcal} \cdot \mathrm{mol}^{-1}{ }^{23}$ Note that the value of $1.26 \mathrm{kcal} \cdot \mathrm{mol}^{-1}$ was computed using experimental data (see Table 4 footnote g). Increasing the theory level to $\mathrm{CCSD}(\mathrm{T}) / \mathrm{aVQZ} / / \mathrm{MP} 2 / \mathrm{aV} 5 \mathrm{Z}$, as reported herein, did not significantly alter the stability of these 


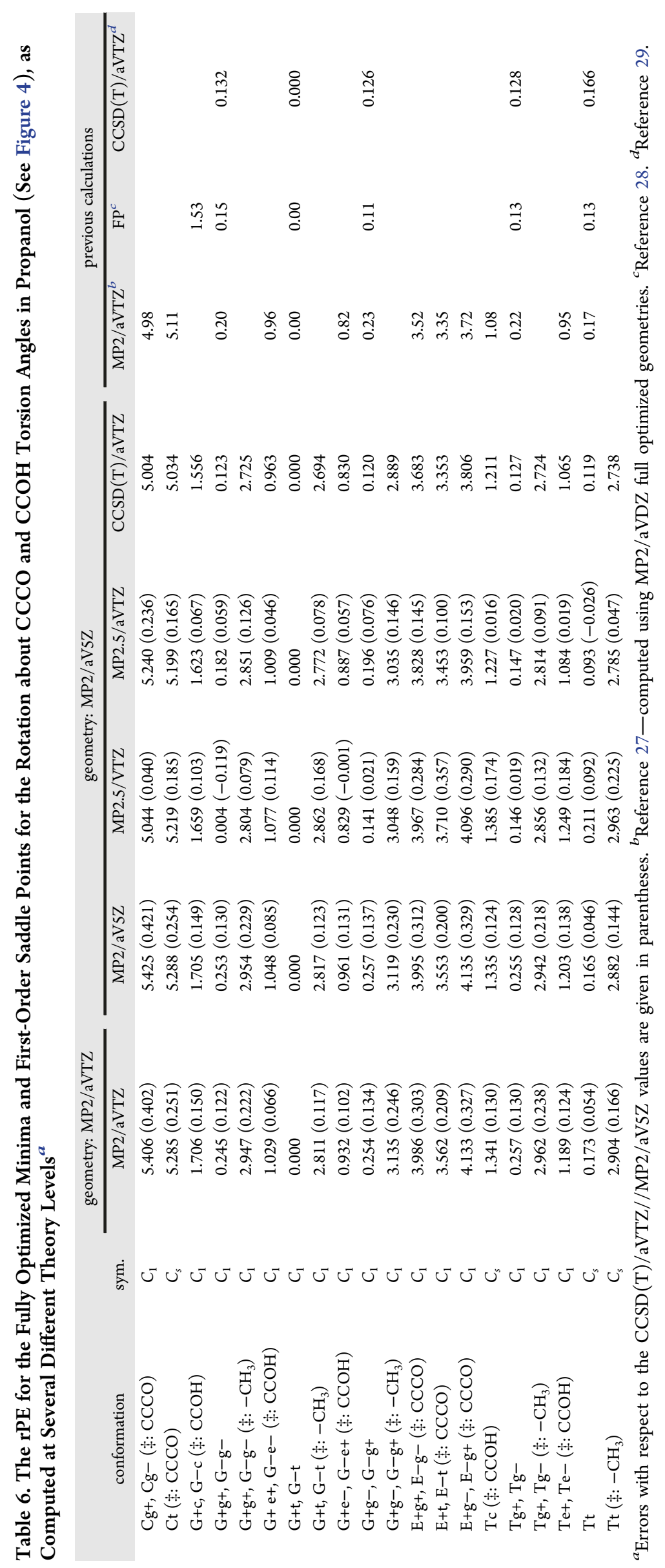


Table 7. Average Absolute Error in the rPE with Respect to $\operatorname{CCSD}(\mathrm{T})$ Values for the Alcohols Investigated Herein and Four Hydrocarbons Reported in Ref 30

\begin{tabular}{|c|c|c|c|c|c|c|}
\hline molecule & number of conformations ${ }^{a}$ & $\mathrm{MP} 2 / \mathrm{aVTZ}^{b}$ & $\mathrm{MP}^{2 / a V 5 Z^{c}}$ & $\mathrm{MP} 2.5 / \mathrm{VTZ}^{c}$ & MP2.5/aVTZ & target $\mathrm{rPE}$ \\
\hline methanol & 1 & 0.026 & 0.005 & 0.091 & $0.036^{c}$ & $\operatorname{CCSD}(\mathrm{T}) / \mathrm{CBS}[\mathrm{aVTZ}, \mathrm{aVQZ}]^{c}$ \\
\hline ethanol & 5 & 0.131 & 0.120 & 0.071 & $0.012^{c}$ & $\operatorname{CCSD}(\mathrm{T}) / \mathrm{aVQZ}^{c}$ \\
\hline propan-2-ol & 6 & 0.137 & 0.151 & 0.119 & $0.071^{c}$ & $\operatorname{CCSD}(\mathrm{T}) / \mathrm{aVTZ}{ }^{c}$ \\
\hline propanol & 19 & 0.184 & 0.186 & 0.145 & $0.088^{c}$ & $\operatorname{CCSD}(\mathrm{T}) / \mathrm{aVTZ}^{c}$ \\
\hline butane & 1 & 0.069 & & & $0.018^{b}$ & $\operatorname{CCSD}(\mathrm{T}) / \mathrm{aVTZ}^{b}$ \\
\hline pentane & 3 & 0.145 & & & $0.028^{b}$ & $\operatorname{CCSD}(\mathrm{T}) / \mathrm{aVTZ}^{b}$ \\
\hline hexane & 11 & 0.183 & & & $0.012^{b}$ & $\operatorname{CCSD}(\mathrm{T}) / \mathrm{VTZ}^{d}$ \\
\hline octane & 3 & 0.175 & & & $0.057^{b}$ & $\operatorname{CCSD}(\mathrm{T}) / \mathrm{aVTZ}{ }^{b}$ \\
\hline
\end{tabular}

${ }^{a}$ The difference in the rPE between the theories for each of the molecule's global minimum was not included in the analysis because it has a value of $0.000 \mathrm{kcal} \cdot \mathrm{mol}^{-1}$ in all cases. ${ }^{b} \mathrm{Geometries}$ were fully optimized at the MP2/aVTZ theory level. ${ }^{c}$ Geometries were fully optimized using at the MP2/ aV5Z theory level. ${ }^{d}$ Reference 31 . Geometries were optimized at the MP2/VTZ theory level.

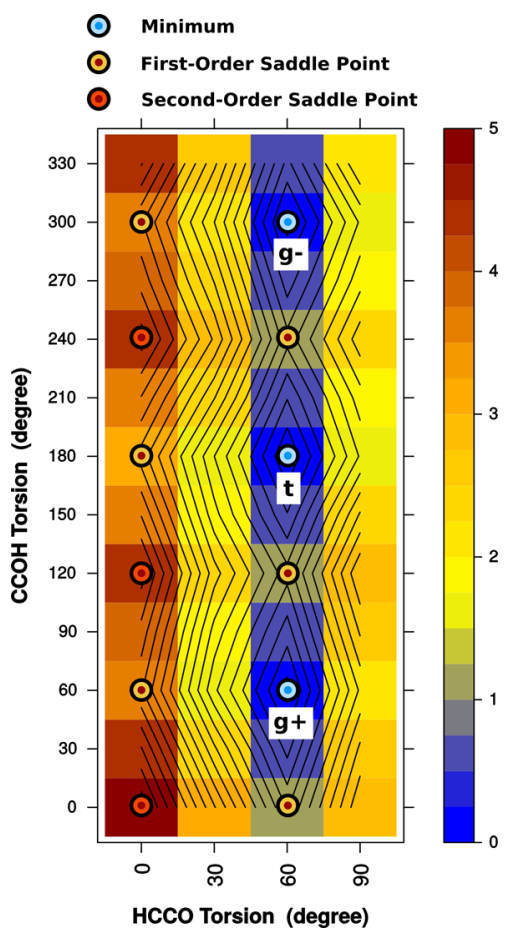

Figure 3. The rPE surface for the rotation of ethanol's HCCO and $\mathrm{CCOH}$ torsion angles computed at the $\mathrm{CCSD}(\mathrm{T}) / \mathrm{aVTZ} / / \mathrm{MP} 2 / \mathrm{aVTZ}$ theory level. The relative energy scale is shown in $0.25 \mathrm{kcal} \cdot \mathrm{mol}^{-1}$ bins. The corresponding relative energy values are given in Supporting Information Table 7.

stationary points (i.e., $0.128,1.095$, and $1.209 \mathrm{kcal} \cdot \mathrm{mol}^{-1}$, Table 4).

In addition to the above six stationary points, there are three more energetically unique first-order saddle points that arise from the methyl rotation [i.e., $\mathrm{t}\left(\ddagger\right.$ : $\left.-\mathrm{CH}_{3}\right)$ and $(+/-)$-gauche $\left.\left(\ddagger:-\mathrm{CH}_{3}\right)\right]$, whose relative barrier heights are experimentally known. To compare these values, we make the assumption that the spectroscopic values are always relative to the local minimum [i.e., to the trans or (+/-)-gauche conformation] and not only to the global minimum. Therefore, the methyl rotational barriers given in Table 4 should be adjusted by the minimum along the $\mathrm{CCOH}$ torsion coordinate, yielding rPE barriers of $3.114 \mathrm{kcal}$. $\mathrm{mol}^{-1}$ for trans $\left(\$:-\mathrm{CH}_{3}\right)$ and $3.400 \mathrm{kcal} \cdot \mathrm{mol}^{-1}$ (i.e., 3.528$\left.0.128 \mathrm{kcal} \cdot \mathrm{mol}^{-1}\right)$ for $(+/-)$-gauche $\left(\$:-\mathrm{CH}_{3}\right)$. These barriers agree well with the experimental values of $3.31-3.55 \mathrm{kcal} \cdot \mathrm{mol}^{-1}$ for trans $\left(\ddagger:-\mathrm{CH}_{3}\right)^{8,23-26}$ and $3.58-3.805 \mathrm{kcal} \cdot \mathrm{mol}^{-1}$ for $(+/-)$-gauche $\left(\$:-\mathrm{CH}_{3}\right){ }^{8,23,26}$
Ethanol is the smallest alcohol that possesses a coupling between two distinct torsions (i.e., $\mathrm{HCCO}$ and $\mathrm{CCOH}$ ). Previous experimental studies showed that the first-order saddle point barrier heights are dependent upon the hydroxyl group adopting a trans or gauche minimum, with trans providing the lower barrier. ${ }^{8,23,25,26}$ We extend this observation by investigating the dependency of the second-order saddle point barriers on the hydroxyl conformation. As seen in Figure 3 and Supporting Information Table 7, the relative barriers of the second-order saddle points (i.e., for when $\mathrm{HCCO}=0^{\circ}$ ) are also dependent upon the conformations adopted by the $\mathrm{CCOH}$ torsion. Thus, the conformations that display the lowest to highest methyl rotation barrier, relative to the global trans minimum are

$$
\begin{aligned}
& \text { trans }\left(\ddagger:-\mathrm{CH}_{3}\right): 3.134 \\
& \quad<(+/-) \text {-eclipse }\left(\ddagger \neq: \mathrm{CCOH} \text { and }-\mathrm{CH}_{3}\right): 3.531 \\
& \quad<(+/-) \text {-gauche }\left(\ddagger:-\mathrm{CH}_{3}\right): 4.370 \\
& \quad<\text { cis }\left(\ddagger \neq: \mathrm{CCOH} \text { and }-\mathrm{CH}_{3}\right): 4.925 \mathrm{kcal} \cdot \mathrm{mol}^{-1}
\end{aligned}
$$

Propan-2-ol. In terms of the spatial arrangement of atoms and intramolecular coordinates, propan-2-ol is very similar to ethanol, but differs by the presence of a symmetrically equivalent methyl group. Consequently, the hydroxyl rotation is a function of two $\mathrm{CCOH}$ torsions and a single $\mathrm{HCCO}$, and can be influenced by the rotation of both methyl groups. The most comprehensive conformational study to date, by Dobrowolski and co-workers, identified two minima, four first-order saddle points, two second-order saddle points, and one third-order saddle point via MP2/VTZ optimizations. ${ }^{40} \mathrm{Kahn}$ and Kahn focal point calculations on both minima and three first-order saddle points represent the most rigorous rPE calculations to date. $^{22}$ Collectively, both studies identified all of the minima and first-order saddle points on propan-2-ol's potential energy surface. Adding to this data, we compute all of the minima and first-order saddle points using a single theory level [i.e., $\operatorname{CCSD}(\mathrm{T})]$, compute the $\mathrm{rPE}$ surface that is formed by the coupling of $\mathrm{HCCO}$ and $\mathrm{CCOH}$ torsions, and subsequently identify second-order saddle points.

Propan-2-ol has three minima [i.e., (+/-)-gauche and trans] that are defined by its hydroxyl orientation (Figure 1). ${ }^{10,22,28,41,42}$ The best focal point calculation predicted the $(+/-)$-gauche to be $0.268 \mathrm{kcal} \cdot \mathrm{mol}^{-1}$ more stable than the trans conformation, ${ }^{22}$ for which $\operatorname{CCSD}(\mathrm{T})$ is in close agreement $\left(0.257 \mathrm{kcal} \cdot \mathrm{mol}^{-1}\right.$, Table 5). These computed values lie in the middle of the experimental range of $0.025-0.450 \mathrm{kcal} \cdot \mathrm{mol}^{-1}$. $12,41,43$

Along the $\mathrm{CCOH}$ internal coordinate pathway, there exist three first-order saddle points [i.e. $\mathrm{e}(+/-),(\ddagger \mathrm{CCOH})$, and $\mathrm{c}$ 
Table 8. Average CCSD(T)/aVTZ rPE of Each Surface Determined by the Coupling of the Terminal Methyl (i.e., HCCx, $\mathrm{x}=\mathrm{C}, \mathrm{O})$ and Hydroxyl (i.e. CCOH) Rotations within Ethanol, Propan-2-ol, (+/-)-Gauche Propanol, and Trans Propanol, as well as Their Differences $^{a}$

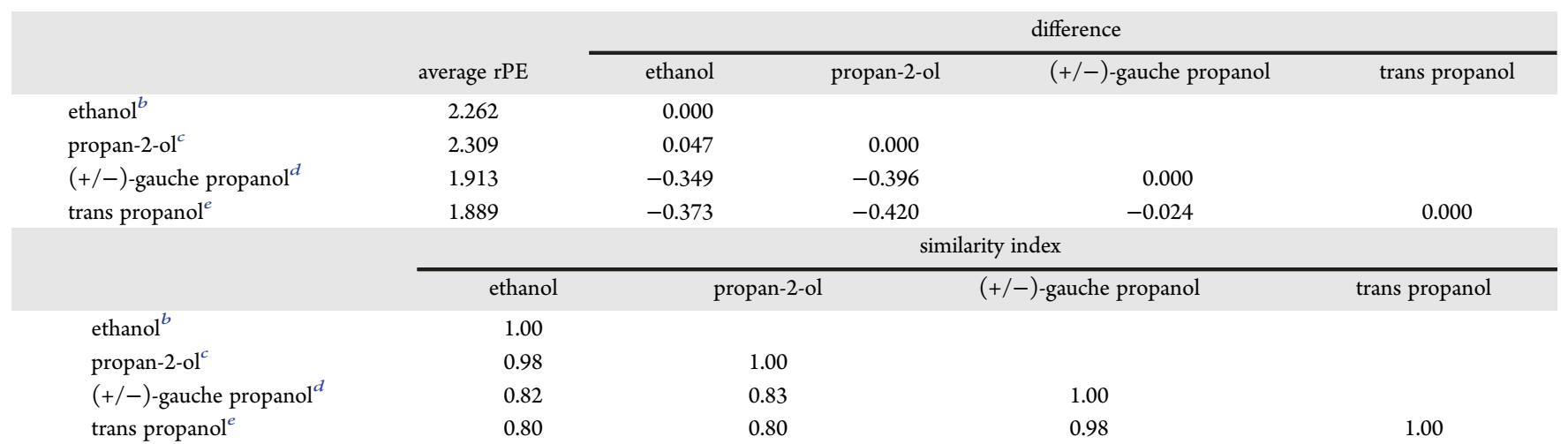

${ }^{a}$ The similarity index computed between each surface is also provided. ${ }^{b}$ The data used are plotted in Figure 3 and given in Supporting Information Table 7. ${ }^{c}$ The data used are plotted in Supporting Information Figure 1 and in Supporting Information Table 8. ${ }^{d}$ The data used are plotted in Figure $\mathrm{Sb}$ and given in Supporting Information Table $11 .{ }^{e}$ The data used are plotted in Figure $5 \mathrm{a}$ and given in Supporting Information Table 10.

$(\ddagger: \mathrm{CCOH})]$ (Figure 1). The cis saddle point, connecting the two gauche conformations, has a barrier of 1.318 and $1.274 \mathrm{kcal}$. $\mathrm{mol}^{-1}$ according to focal point ${ }^{22}$ and $\operatorname{CCSD}(\mathrm{T})$ calculations. Similarly, the $(+/-)$-eclipse saddle points, connecting the $(+/-)$-gauche and trans conformations, have a focal point and $\operatorname{CCSD}(\mathrm{T})$ barrier of $1.143^{22}$ and $1.142 \mathrm{kcal} \cdot \mathrm{mol}^{-1}$, which are notably lower than the experimental value of $1.68 \mathrm{kcal} \cdot \mathrm{mol}^{-1} .10$ Note that the focal point papers reference experimental values of 1.54 and $1.24 \mathrm{kcal} \cdot \mathrm{mol}^{-1}$ for the two hydroxyl rotation barriers, ${ }^{22,28}$ citing microwave spectroscopy studies. ${ }^{44,45}$ However, we were unable to verify these two values from the original source.

The remaining three energetically unique saddle points correspond to the rotation of one methyl group with respect to the three possible hydroxyl minima [i.e., $\mathrm{g}+\left(\ddagger:-\mathrm{CH}_{3} \mathrm{a}\right), \mathrm{g}-(\ddagger$ : $\left.-\mathrm{CH}_{3} \mathrm{a}\right)$, and $\left.\mathrm{t}\left(\ddagger \mathrm{:}-\mathrm{CH}_{3} \mathrm{a}\right)\right]$. These saddle points also have their own isomers that occur when the second methyl group (i.e., $\left.-\mathrm{CH}_{3} \mathrm{~b}\right)$ rotates instead. Note that the (+)-gauche and (-)-gauche conformations are not equivalent because they have different orientations with respect to the rotating methyl group (see Figure 1). As seen in ethanol and based on the rPE that references the global minimum (Table 5), the methyl rotation barrier is dependent upon the orientation of the hydroxyl group. The conformations that display the lowest to highest methyl rotation barrier, relative to the global $(+/-)$-gauche minima are

$$
\begin{aligned}
& (+) \text {-gauche }\left(\ddagger:-\mathrm{CH}_{3} \mathrm{a}\right): 3.148 \\
& \quad<(-) \text {-gauche }\left(\ddagger:-\mathrm{CH}_{3} \mathrm{a}\right): 3.482 \\
& \quad<\text { trans }\left(\ddagger:-\mathrm{CH}_{3}\right): 3.728 \mathrm{kcal} \cdot \mathrm{mol}^{-1}
\end{aligned}
$$

Adjusting the methyl rotational barriers that are given in Table 5 by the $\mathrm{rPE}$ of their respective local minimum results in $\operatorname{CCSD}(\mathrm{T})$ energies of $3.148,3.482$, and $3.471 \mathrm{kcal} \cdot \mathrm{mol}^{-1}$ when the molecule adopts (+)-gauche, (-)-gauche, and trans conformations, respectively. There remains a clear differentiation between the methyl rotation for the $(+)$-gauche and $(-)$-gauche conformations as well as for the $(+)$-gauche and trans conformations. However, the methyl rotation barriers for (-)-gauche and trans become nearly equivalent (i.e., a 0.011 $\mathrm{kcal} \cdot \mathrm{mol}^{-1}$ difference). For comparison to previous work, only one of the gauche barriers was computed using focal point calculations-yielding a value of $3.189 \mathrm{kcal} \cdot \mathrm{mol}^{-1} \cdot{ }^{22}$ On the basis of its magnitude, it is assumed that this value is for the $(+)$-gauche conformation [i.e., g+ $\left(\ddagger-\mathrm{CH}_{3}\right.$ a) ].

Qualitatively, the ethanol's (Figure 3) and propan-2-ol's (Supporting Information Figure 2) surfaces formed by the $\mathrm{HCCO}$ and $\mathrm{CCOH}$ couplings are nearly identical. In an attempt to quantify the overall repulsiveness of surfaces involving the methyl rotation by a single metric, an average rPE for each surface was computed to be 2.262 and $2.309 \mathrm{kcal} \cdot \mathrm{mol}^{-1}$ (Table 8 ). A difference between the resulting averaged rPEs provides a relative scale for identifying if one surface is more or less repulsive than another. This difference shows that the rPE of the propan-2ol and ethanol surfaces are, on average, within $0.047 \mathrm{kcal} \cdot \mathrm{mol}^{-1}$ of each other. Furthermore, a similarity index was computed between the two surfaces (Table 8), resulting in a value of 0.98 . Both of these approaches confirm that propan-2-ol's and ethanol's methyl rotation surfaces are essentially identical.

Propanol. Propanol, because of its additional carbene group (i.e., $-\mathrm{CH}_{2}-$ ), has five potential energy surfaces (Figures 4 and 5) that can be described by the coupling of

(a) the $\mathrm{CCCO}$ and $\mathrm{CCOH}$ torsions,

(b) the methyl rotation and $\mathrm{CCCO}$, with $\mathrm{CCOH}$ adopting a trans conformation,

(c) the methyl rotation and $\mathrm{CCCO}$, with $\mathrm{CCOH}$ adopting a $(+/-)$-gauche conformation,

(d) the methyl rotation and $\mathrm{CCOH}$, with $\mathrm{CCCO}$ adopting a trans conformation and

(e) the methyl rotation and $\mathrm{CCOH}$, with $\mathrm{CCCO}$ adopting a $(+/-)$-gauche conformation.

The first three surfaces are formed by rotating around adjacent torsion angles, whereas the last two are defined by torsions that are separated by one bond. Through the overall generation of these surfaces, all of propanol's minima, first-order, and secondorder saddle points could be characterized at the $\operatorname{CCSD}(\mathrm{T})$ theory level. Note that these surfaces overlap to some extent because certain conformations or their isomers are represented multiple times (e.g., $\mathrm{Tg}+$ and $\mathrm{G}+\mathrm{t} / \mathrm{G}-\mathrm{t}$ ).

The most complex and varied surface is formed by the CCCO and $\mathrm{CCOH}$ torsions (Figure 4). Apart from the stationary points sampled during methyl rotation, this surface displays all of propanol's minima, first-order, and second-order saddle points. The surface is symmetric about CCCO's $180^{\circ}$ - considering the whole surface (i.e., $\mathrm{CCCO}=0-330^{\circ}$ ), a total of nine minima, 


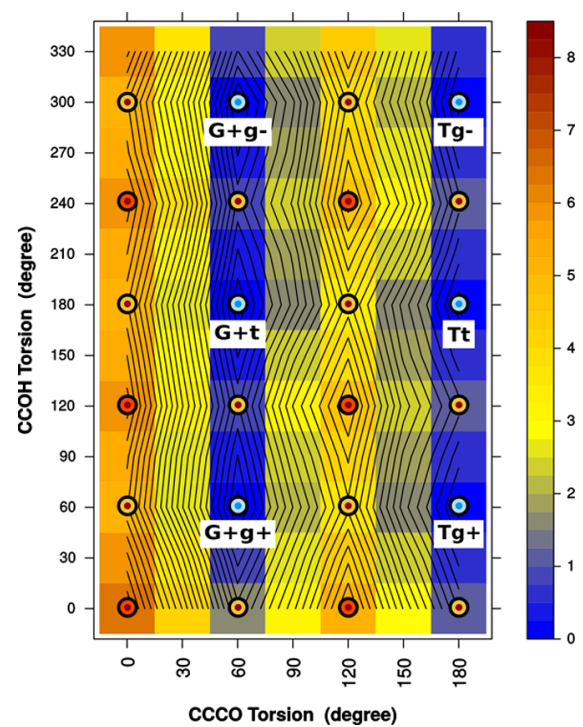

Figure 4. The rPE surface for the rotation of propanol's CCCO and $\mathrm{CCOH}$ torsion angles computed at the $\mathrm{CCSD}(\mathrm{T}) / \mathrm{aVTZ} / / \mathrm{MP} 2 / \mathrm{aVTZ}$ theory level. The rPE scale is shown in $0.25 \mathrm{kcal} \cdot \mathrm{mol}^{-1}$ bins, which ranges from the global minimum to the global maximum for all propanol surfaces computed (see also Figure 5). The $\operatorname{CCSD}(\mathrm{T}) / \mathrm{aVTZ}$ energies are given in Supporting Information Table 9.

eighteen first-order and nine second-order saddle points exist Out of the nine minima, eight exist as enantiomeric pairs and one (i.e., $\mathrm{Tt}$ ) is an energetically unique minima (Table 6). The experimental information regarding the relative stability of propanol's minima is unclear because of vague identifications and contradictions within the literature. ${ }^{13,14,46,47}$ However, focal point calculations clearly predicted the rPE ordering of the minima, with the $\mathrm{G}+\mathrm{t}$ and $\mathrm{G}-\mathrm{t}$ enantiomeric pair being the global minima. ${ }^{27,28}$ According to the focal point and $\operatorname{CCSD}(\mathrm{T})$ calculations, the remaining minima (i.e., $\mathrm{G}+\mathrm{g}+, \mathrm{G}-\mathrm{g}-, \mathrm{G}+\mathrm{g}-$, $\mathrm{G}-\mathrm{g}+, \mathrm{Tg}+, \mathrm{Tg}-$, and $\mathrm{Tt}$ ) are within a small energetic range of $0.11-0.13 \mathrm{kcal} \cdot \mathrm{mol}^{-1}$ of the global minima (Table 6).

Previously, the most comprehensive study of the minima and first-order saddle points was performed using the MP2/aVTZ// MP2/VDZ theory level by Kahn and Bruice, ${ }^{27}$ but excluded six first-order saddle points (see Table 6). The first-order saddle points with the largest rotational barrier, relative to the global minima, have the CCCO torsion adopting a cis conformation (i.e., $\mathrm{Cg}+, \mathrm{Cg}-$, and $\mathrm{Ct}$ ) with essentially equivalent barriers of 5.004 and $5.034 \mathrm{kcal} \cdot \mathrm{mol}^{-1}$ (Table 6). These barriers connect the $(+)$-gauche and $(-)$-gauche CCCO conformational minima (i.e., $\mathrm{G}+\mathrm{g}+, \mathrm{G}-\mathrm{g}-, \mathrm{G}+\mathrm{g}-, \mathrm{G}-\mathrm{g}+, \mathrm{G}+\mathrm{t}$, and $\mathrm{G}-\mathrm{t})$. The next largest barrier occurs when the CCCO torsion adopts a (+/-)-eclipse conformation (i.e., $\mathrm{E}+\mathrm{g}+, \mathrm{E}-\mathrm{g}-, \mathrm{E}+\mathrm{t}, \mathrm{E}-\mathrm{t}, \mathrm{E}+\mathrm{g}-$, and $\mathrm{E}-\mathrm{g}+$ ), with energies that range from 3.353 to $3.806 \mathrm{kcal} \cdot \mathrm{mol}^{-1}$ that connect the (+/-)-gauche (i.e., G+g+, G-g-, G+g-, G-g+, G $+\mathrm{t}$, and $\mathrm{G}-\mathrm{t}$ ) and trans conformational minima (i.e., $\mathrm{Tg}+, \mathrm{Tg}-$, and $\mathrm{Tt}$ ).

Along the $\mathrm{CCOH}$ coordinate, the first-order saddle points that have the lowest rotational barriers are when the $\mathrm{CCOH}$ torsion adopts a (+/-)-eclipse (i.e., G+e-, G-e+, G+e+, and G-e-) conformation, with energies ranging from 0.830 to $1.065 \mathrm{kcal}$. $\mathrm{mol}^{-1}$. Occurring at slightly higher barriers are the $\mathrm{CCOH}$ torsions that adopt a cis conformation (i.e., $\mathrm{G}+\mathrm{c}, \mathrm{G}-\mathrm{c}$, and $\mathrm{Tc}$ ), with energies of 1.211 and $1.556 \mathrm{kcal} \cdot \mathrm{mol}^{-1}$. All of the secondorder saddle points that are defined by the $\mathrm{CCCO}$ and $\mathrm{CCOH}$ torsions (i.e., $\mathrm{Ce}+, \mathrm{Ce}-, \mathrm{Cc}, \mathrm{E}+\mathrm{c}, \mathrm{E}+\mathrm{e}+, \mathrm{E}+\mathrm{e}-, \mathrm{E}-\mathrm{e}+, \mathrm{E}-\mathrm{e}-$, and $\mathrm{E}-\mathrm{c}$ ) have relative energies that range between 4.555 and 6.467 $\mathrm{kcal} \cdot \mathrm{mol}^{-1}$ (Supporting Information Table 9), with the least stable conformation having both torsion angles adopt a cis conformation (i.e., Cc). Given a limited amount of absorbed energy, the CCCO conversion from $(+/-)$-gauche to trans would preferentially go through the eclipsed first-order saddle points rather than the cis saddle point.

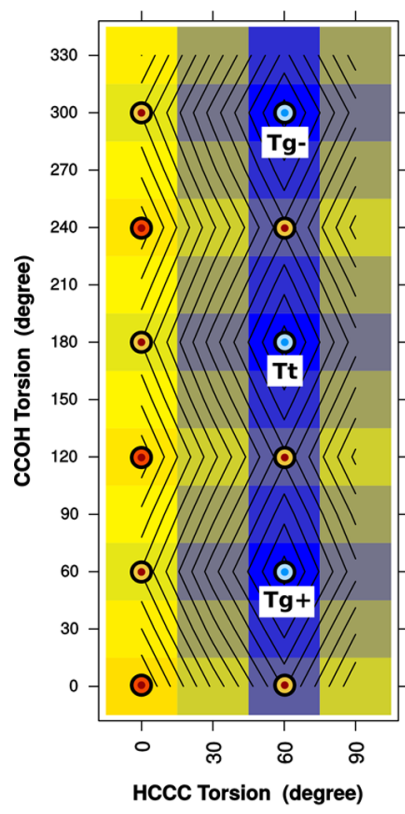

(a) $\mathrm{CCCO}=$ trans

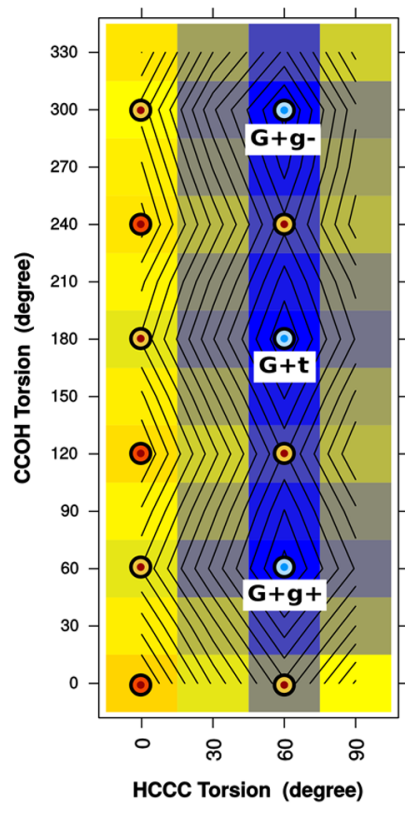

(b) $\mathrm{CCCO}=(+)$-gauche

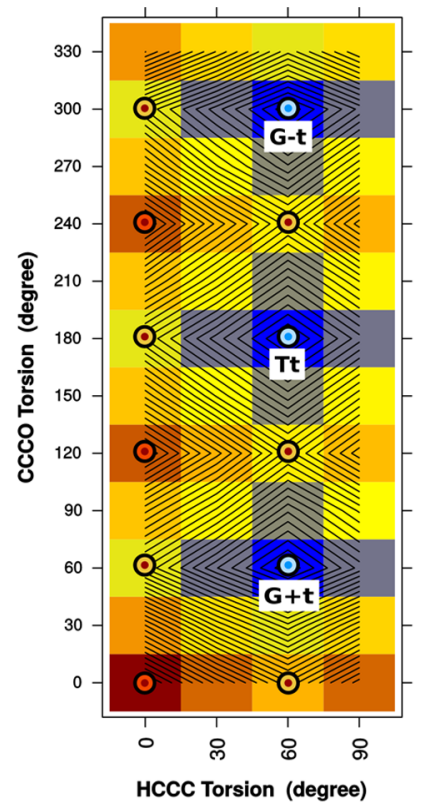

(c) $\mathrm{CCOH}=$ trans

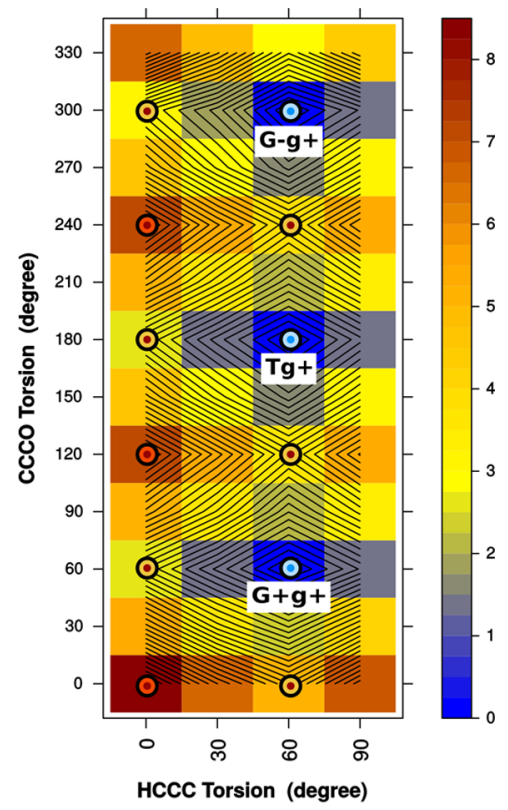

(d) $\mathrm{CCOH}=(+)$-gauche

Figure 5. $\mathrm{CCSD}(\mathrm{T}) / \mathrm{aVTZ} / / \mathrm{MP} 2 / \mathrm{aVTZ} \mathrm{rPE}$ surface for the rotational coupling of propanol's terminal methyl group with the $\mathrm{CCOH}$ (a,b) and CCCO $(\mathrm{c}, \mathrm{d})$ torsion angles. The relative energy scale is shown in $0.25 \mathrm{kcal} \cdot \mathrm{mol}^{-1}$ bins, which ranges from the global minimum to the global maximum for all propanol surfaces computed. The CCSD $(\mathrm{T})$ energies are given in Supporting Information Tables 10-13. 
Regarding the methyl rotation, the surfaces formed by the coupling between the adjacent HCCC and CCCO torsions display little dependency upon the conformations that the hydroxyl group adopts (Figure 5c,d, and Supporting Information Tables 12 and 13). The average CCSD (T)/aVTZ rPE of each of these surfaces is 3.450 and $3.510 \mathrm{kcal} \cdot \mathrm{mol}^{-1}$, a $0.189 \mathrm{kcal} \cdot \mathrm{mol}^{-1}$ difference between them; computing the similarity between these two surfaces results in a value of 0.95 . Both of these metrics support the observation that the two surfaces are similar.

Ordering the conformations such that they display the lowest to highest methyl rotational barriers (Table 6), relative to the global minimum, leads to

$$
\begin{aligned}
\mathrm{G}+\mathrm{t}, \mathrm{G}-\mathrm{T}\left(\$:-\mathrm{CH}_{3}\right): 2.694 \\
\quad<\mathrm{Tg}+, \mathrm{Tg}-, \mathrm{G}+\mathrm{g}+, \mathrm{G}-\mathrm{g}-\left(\ddagger:-\mathrm{CH}_{3}\right): 2.725(1) \\
\quad<\mathrm{Tt}\left(\ddagger:-\mathrm{CH}_{3}\right): 2.738 \\
\quad<\mathrm{G}+\mathrm{G}-, \mathrm{G}-\mathrm{g}+\left(\ddagger:-\mathrm{CH}_{3}\right): 2.889 \mathrm{kcal} \cdot \mathrm{mol}^{-1}
\end{aligned}
$$

Notice that all of these barriers are lower than those seen in ethanol and propan-2-ol, whose lowest barrier was $3.134 \mathrm{kcal}$. $\mathrm{mol}^{-1}$. Adjusting these barriers by their local minimum (i.e., $\mathrm{G}+\mathrm{t}$, $\mathrm{G}-\mathrm{t}, \mathrm{G}+\mathrm{g}+, \mathrm{G}-\mathrm{g}+, \mathrm{Tt}$, and $\mathrm{Tg}+$ ) results in energies that range from 2.597 to $2.769 \mathrm{kcal} \cdot \mathrm{mol}^{-1}$. Thus, all nine methyl rotor barrier heights occur within a narrow $0.172 \mathrm{kcal} \cdot \mathrm{mol}^{-1}$ window of one another. Consequently, their individual identification might be difficult to achieve spectroscopically. This also further supports the observation that the hydroxyl orientation has only a small effect on the methyl rotation. Experimentally, the methyl barrier dependency upon the $\mathrm{CCCO}$ and $\mathrm{CCOH}$ torsions has been investigated, but the literature is unclear with regard to the specific conformations studied. ${ }^{13,46}$ What can be definitively stated is that the experimental work finds that the methyl barrier ranges from $2.620 \pm 0.050$ to $3.080 \pm 0.050 \mathrm{kcal} \cdot \mathrm{mol}^{-1}, 13,14,46$ with the lower values agreeing well with the $\operatorname{CCSD}(\mathrm{T})$ values.

A comparison of the methyl rotational surfaces, as defined between the $\mathrm{CCOH}$ and $\mathrm{HCCn}$ ( where $\mathrm{n}=\mathrm{C}$ or O) torsions, can be made for ethanol, propan-2-ol, (+/-)-gauche propanol, and trans propanol (Figures 3, 5a,b and Supporting Information Figure 2$)$. The (+/-)-gauche and trans propanol rPE surfaces are less repulsive than those for ethanol and propan-2-ol, with average surface rPEs of 1.913 and $1.889 \mathrm{kcal} \cdot \mathrm{mol}^{-1}$ (Table 8). This reduced repulsion can be attributed to the longer distance between the terminal methyl and hydroxyl groups because of the additional carbene group that is present. The differences between the propanol surfaces and those of ethanol and propan-2-ol are further exemplified by their low similarity indexes, with values that range from 0.80 to 0.83 . However, note that the $(+/-)$-gauche and trans propanol surfaces are themselves similar, with a difference in their average surface rPEs of 0.024 $\mathrm{kcal} \cdot \mathrm{mol}^{-1}$ and a similarity index of 0.98 .

\section{CONCLUSIONS}

In this paper, we present an extensive investigation of the minima and first-order saddle points for methanol, ethanol, propan-2-ol, and propanol. All geometries were fully optimized at the MP2/ aV5Z theory level, whereas the rPEs were computed using $\operatorname{CCSD}(\mathrm{T})$. For the first time, we identify all minima and firstorder saddle points for ethanol, propan-2-ol, and propanol within a consistent theoretical framework. Frequency analyses were performed at the MP2/aVTZ//MP2/aVTZ theory level to verify the fully optimized stationary point positions on their potential energy surfaces. A comparison of rotational constants to experimentally known values showed that geometries optimized using MP2/aVTZ were reliable. Furthermore, seven rPE surfaces were computed at the $\operatorname{CCSD}(\mathrm{T}) / \mathrm{aVTZ} / / \mathrm{MP} 2 / \mathrm{aVTZ}$ theory level. These surfaces subsequently allowed us to identify secondorder saddle points.

Building on previous results for linear-saturated hydrocarbons, ${ }^{30}$ we investigated how well MP2.5 performs at reproducing $\operatorname{CCSD}(\mathrm{T})$ relative energies for small alcohols. In general, MP2.5 provides rPEs that are close to the best $\operatorname{CCSD}(\mathrm{T})$ values computed using reliable small alcohol geometries. Specifically, MP2.5/aVTZ//MP2/aV5Z had an average error of $0.081 \mathrm{kcal} \cdot \mathrm{mol}^{-1}$ with respect to $\operatorname{CCSD}(\mathrm{T}) / \mathrm{aVTZ} / / \mathrm{MP} 2 /$ aV5Z rPEs. However, MP2.5 rPEs can deviate significantly from the $\operatorname{CCSD}(\mathrm{T})$ values, as seen for several individual propanol conformations-this being especially true when used in conjunction with the smaller VTZ basis set.

Several general observations can be made from the data presented herein. As anticipated, methyl rotation is most affected by the conformations that are adopted by adjacent torsion angles. This was demonstrated by the comparison of the rPE surfaces formed by the coupling between HCCn (where $n=O$ or C) and the $\mathrm{CCOH}$ torsion in ethane and propane.

The first-order saddle points for methyl rotation in ethanol and propan-2-ol show a clear energetic dependency and separation upon the hydroxyl orientation when the rPEs are computed in reference to each of the molecules' global minimum. However, if the rPEs are adjusted by their local minimum, the methyl barriers for propan-2-ol's $(-)$-gauche and trans conformations become equivalent.

The rPE surfaces of ethanol and propan-2-ol formed by the coupling of $\mathrm{HCCO}$ and $\mathrm{CCOH}$ torsions are nearly identical, displaying average $\mathrm{rPEs}$ of 2.262 and $2.309 \mathrm{kcal} \cdot \mathrm{mol}^{-1}(\Delta=0.047$ $\left.\mathrm{kcal} \cdot \mathrm{mol}^{-1}\right)$ and a similarity index of 0.98 . These surfaces are significantly different from propanol's two comparable surfaces that are formed by $\mathrm{HCCC}$ and $\mathrm{CCOH}$, exemplified by similarity indexes that range from 0.80 to 0.83 . Note that these two propanol surfaces are themselves highly similar, with average rPEs of 1.913 and $1.889 \mathrm{kcal} \cdot \mathrm{mol}^{-1}$ and a similarity index of 0.98 .

Likewise, the two propanol surfaces formed by the coupling of HCCC and CCCO are also highly similar, with a similarity index of 0.95 . The average rPEs of the two surfaces are larger than those mentioned above, with values of 3.450 and $3.510 \mathrm{kcal} \cdot \mathrm{mol}^{-1}$. Furthermore, all of propanol's methyl rotational barriers are energetically lower than those found in ethanol and propan-2-ol, whereas methanol possesses the lowest barrier of all those studied. Finally, because of its additional carbene group, propanol possesses the largest number of minima and firstorder saddle points of the molecules studied. A total of thirty-six stationary points were fully optimized and characterized.

It would also be possible to alternatively use Jensen basis sets ${ }^{48-50}$ in the calculations, which might reduce the calculation cost. These basis sets were originally designed for use in Hartree-Fock and density functional theories. There have been two studies that discuss their usage in MP2 and $\operatorname{CCSD}(\mathrm{T})$ calculations, ${ }^{51,52}$ showing a somewhat mixed result that depends on the system being investigated (i.e., isolated molecules vs weakly bound clusters). We intend to investigate this further in the near future.

\section{METHODOLOGY}

Fully relaxed density-fitted (DF) $)^{53-55} \mathrm{HF} / 6-31 \mathrm{G}(\mathrm{d})$ and $\mathrm{MP} 2^{56}$ optimizations were performed on all minima and first-order saddle points until a maximum force of $1.5 \times 10^{-5}$, RMS force of $1.0 \times 10^{-5}$, maximum displacement of $6.0 \times 10^{-5}$, and RMS 
displacement of $4.0 \times 10^{-5}$ (i.e., a tight convergence) were achieved. The DF-MP2 optimization employed 6-31G(d), ccpVTZ (VTZ), aug-cc-pVTZ (aVTZ), cc-pVQZ (VQZ), aug-ccpVQZ (aVQZ), and aug-cc-pV5Z (aV5Z) basis sets. ${ }^{57-60}$ As part of the DF-MP2 calculations, the self-consistent field reference energies were also computed using the DF approximation with the appropriate corresponding auxiliary basis sets. ${ }^{61-63}$ All optimizations were performed using $C_{1}$ molecular symmetry, whereas the symmetry groups reported in the tables were obtained through an analysis of the fully optimized geometries using the Symmetrizer program. ${ }^{64}$ A frequency analysis was performed at the MP2/aVTZ//MP2/aVTZ theory level for each minimum and first-order saddle point. Second-order saddle points were identified based on their position on the computed rPE surfaces.

The rPEs were computed at MP2.5 $5^{65,66}$ and $\operatorname{CCSD}(\mathrm{T})^{67-69}$ theory levels by performing a single self-consistent field evaluation upon the fully optimized geometries. Extrapolations to the complete-basis-set (CBS) limit were done using the twopoint scheme of Helgaker and co-workers; ${ }^{70}$ the two basis sets used in the extrapolation are presented within square brackets. For the generation of the rPE surfaces, all geometry optimizations were done using traditional MP2 calculations (i.e., without DF approximation). Because of its prevalent use and discussion, the $\operatorname{CCSD}(\mathrm{T}) / \mathrm{aVTZ} / / \mathrm{MP} 2 / \mathrm{aVTZ}$ theory level will be abbreviated simply as $\operatorname{CCSD}(\mathrm{T})$. In all correlated calculations, the core orbitals were frozen. All constraint optimizations associated with rPE surfaces were computed using the Gamess program (v. 1 MAY 2013 (R1)). ${ }^{71,72}$ All other calculations were performed using the Psi4 program (v. 1.1a2.dev170)..$^{73,74}$

For unique identification of each conformation, we make use of the previously established nomenclature. ${ }^{47,75}$ Table 9 provides

Table 9. Nomenclature and Their Abbreviations Based on a Torsion Range (in Degrees)

\begin{tabular}{|c|c|c|c|}
\hline \multirow[b]{2}{*}{ nomenclature } & \multicolumn{2}{|c|}{ abbreviations } & \multirow[b]{2}{*}{ torsion $(\phi)$ range } \\
\hline & $\begin{array}{l}\text { torsions } \\
\text { involving } \\
\mathrm{CCCO}\end{array}$ & $\begin{array}{l}\text { torsions involving the } \\
\text { hydroxyl's hydrogen } \\
\text { atom }\end{array}$ & \\
\hline$(+)$-gauche & G+ & $g+$ & $30.0<\phi \leq 90.0$ \\
\hline (+)-eclipse & $\mathrm{E}+$ & $\mathrm{e}+$ & $90.0<\phi \leq 150.0$ \\
\hline trans & $\mathrm{T}$ & $t$ & $150.0<\phi \leq 210.0$ \\
\hline (-)-eclipse & E- & $\mathrm{e}-$ & $210.0<\phi \leq 270.0$ \\
\hline (-)-gauche & G- & $g-$ & $270.0<\phi \leq 330.0$ \\
\hline cis & $\mathrm{C}$ & c & $\begin{array}{c}330.0<\phi \leq 360.0 \\
\text { and } 0.0 \leq \phi \leq 30.0\end{array}$ \\
\hline
\end{tabular}

the full nomenclature, including associated angle ranges used to classify the conformations. The conformations adopted by the hydroxyl rotation are abbreviated using a lower case letter, whereas those adopted by propanol's CCCO torsion are abbreviated using an upper case letter. ${ }^{47}$ The direction of torsion rotation is indicated by + and - symbols. ${ }^{75}$ The first-order saddle points are indicated using a $\ddagger$ symbol and accompanied by the torsion's atomic sequence that characterizes the transition state (e.g., †: $\mathrm{CCOH}$ ).

\section{ASSOCIATED CONTENT}

\section{S Supporting Information}

The Supporting Information is available free of charge on the ACS Publications website at DOI: 10.1021/acsomega.7b01367.
1. CCSD(T)/aVTZ//MP2/aVTZ (fully optimized structures and surfaces) and $\operatorname{CCSD}(\mathrm{T}) / \mathrm{aVTZ} / / \mathrm{MP} 2 / \mathrm{aV} 5 \mathrm{Z}$ (fully optimized structures) energies (Hartree): raw_data_energies (XLSX)

2. All fully optimized minima and first-order saddle point geometries, with tight convergence criteria, computed at density-fitted MP2/aV5Z//MP2/aV5Z provided in the following xyz-formated files:

(a) methanol_archive_structures (XYZ)

(b) ethanol_archive_structures (XYZ)

(c) propan-2-ol_archive_structures (XYZ)

(d) propanol_archive_structures (XYZ)

3. Additional data and figures:

(a) Fully optimized structures and nomenclature for methanol and ethanol minima and first-order saddle points as computed by MP2/aV5Z

(b) Selected internal coordinate values for all studied conformations and first-order transition states

(c) RMSD for all minima and first-order saddle point structures studied

(d) $\operatorname{CCSD}(\mathrm{T}) / \mathrm{aVTZ} / / \mathrm{MP} 2 / \mathrm{aVTZ} \mathrm{rPE}$ surface for the rotational coupling of one of the propan-2-ol's terminal methyl group with the $\mathrm{CCOH}$ torsion angle

(e) Additional rPE for the fully optimized minima and first-order saddle points for the rotation about CCCO and $\mathrm{CCOH}$ torsions in propanol

(f) $\operatorname{CCSD}(\mathrm{T}) / \mathrm{aVTZ} / / \mathrm{MP} 2 / \mathrm{aVTZ} \mathrm{rPE}$ used in generating the surface and curve figures (PDF)

\section{AUTHOR INFORMATION}

\section{Corresponding Author}

*E-mail: karl.kirschner@h-brs.de (K.N.K.).

ORCID 웅

Karl N. Kirschner: 0000-0002-4581-920X

Dirk Reith: 0000-0003-1480-6745

Notes

The authors declare no competing financial interest.

\section{ACKNOWLEDGMENTS}

We would like to thank Rudolf Berrendorf and Javed Razzaq for their continuous support of the university's high-performance computing cluster. Computer hardware was supported by the Ministry for Innovation, Science, Research, and Technology of the state Northrhein-Westphalia [Research Grants FH-Basis 2012 and GER08-16].

\section{REFERENCES}

(1) Bak, K. L.; Gauss, J.; Jørgensen, P.; Olsen, J.; Helgaker, T.; Stanton, J. F. The accurate determination of molecular equilibrium structures. $J$. Chem. Phys. 2001, 114, 6548-6556.

(2) Heckert, M.; Kállay, M.; Tew, D. P.; Klopper, W.; Gauss, J. Basis-set extrapolation techniques for the accurate calculation of molecular equilibrium geometries using coupled-cluster theory. J. Chem. Phys. 2006, 125, 044108 .

(3) Shepard, R.; Kedziora, G. S.; Lischka, H.; Shavitt, I.; Müller, T.; Szalay, P. G.; Kállay, M.; Seth, M. The accuracy of molecular bond lengths computed by multireference electronic structure methods. Chem. Phys. 2008, 349, 37-57.

(4) Puzzarini, C. Accurate molecular structures of small- and mediumsized molecules. Int. J. Quantum Chem. 2016, 116, 1513-1519.

(5) Johnson, R. D., III NIST Computational Chemistry Comparison and Benchmark Database. NIST Standard Reference Database Number 101. http://cccbdb.nist.gov, Release Oct 18, 2016. 
(6) Herbst, E.; Messer, J.; De Lucia, F. C.; Helminger, P. A new analysis and additional measurements of the millimeter and submillimeter spectrum of methanol. J. Mol. Spectrosc. 1984, 108, 42-57.

(7) De Lucia, F. C.; Herbst, E.; Anderson, T.; Helminger, P. The analysis of the rotational spectrum of methanol to microwave accuracy. $J$. Mol. Spectrosc. 1989, 134, 395-411.

(8) Kakar, R. K.; Quade, C. R. Microwave rotational spectrum and internal rotation in gauche ethyl alcohol. J. Chem. Phys. 1980, 72, 43004307.

(9) Lovas, F. J. Microwave Spectra of Molecules of Astrophysical Interest. XXI. Ethanol (C2H5OH) and Propionitrile (C2H5CN). J. Phys. Chem. Ref. Data 1982, 11, 251-312.

(10) Kondo, S.; Hirota, E. Microwave spectrum and internal rotation of isopropyl alcohol. J. Mol. Spectrosc. 1970, 34, 97-107.

(11) Ulenikov, O. N.; Malikova, A. B.; Qagar, C. O.; Musaev, S. A.; Adilov, A. A.; Mehtiev, M. I. On the analysis of the gauche-form microwave spectrum of the isopropyl alcohol molecule. J. Mol. Spectrosc. 1991, 145, 262-269.

(12) Hirota, E. Internal rotation in isopropyl alcohol studied by microwave spectroscopy. J. Phys. Chem. 1979, 83, 1457-1465.

(13) Abdurahmanov, A. A.; Rahimova, R. A.; Imanov, L. M. Microwave spectrum of normal propyl alcohol. Phys. Lett. A 1970, 32, 123-124.

(14) Dreizier, H.; Scappini, F. Centrifugal Distortion and Internal Rotation Analysis in the Ground State of Trans N-Propanol. Z. Naturforsch., A: Phys. Sci. 1981, 36, 1187-1191.

(15) Petke, J. Cumulative and discrete similarity analysis of electrostatic potentials and fields. J. Comput. Chem. 1993, 14, 928-933.

(16) Tasi, G.; Nagy, B.; Matisz, G.; Tasi, T. S. Similarity analysis of the conformational potential energy surface of n-pentane. Comput. Theor. Chem. 2011, 963, 378-383.

(17) Miani, A.; Hänninen, V.; Horn, M.; Halonen, L. Anharmonic force field for methanol. Mol. Phys. 2000, 98, 1737-1748.

(18) Koput, J. The Equilibrium Structure and Torsional Potential Energy Function Of Methanol and Silanol. J. Phys. Chem. A 2000, 104, 10017-10022.

(19) Kahn, K.; Bruice, T. C. Systematic convergence of energies with respect to basis set and treatment of electron correlation: focal-point conformational analysis of methanol. Theor. Chem. Acc. 2004, 111, 1824.

(20) Lees, R. M.; Baker, J. G. Torsion-Vibration-Rotation Interactions in Methanol. I. Millimeter Wave Spectrum. J. Chem. Phys. 1968, 48, 5299-5318.

(21) Dyczmons, V. Dimers of Ethanol. J. Phys. Chem. A 2004, 108, 2080-2086.

(22) Kahn, K.; Kahn, I. Improved efficiency of focal point conformational analysis with truncated correlation consistent basis sets. J. Comput. Chem. 2008, 29, 900-911.

(23) Durig, J. R.; Larsen, R. A. Torsional vibrations and barriers to internal rotation for ethanol and 2,2,2-trifluoroethanol. J. Mol. Struct. 1990, 238, 195-222.

(24) Sasada, Y. Excited states of trans ethyl alcohol by microwave spectroscopy. J. Mol. Struct. 1988, 190, 93-97.

(25) Pearson, J. C.; Sastry, K. V. L. N.; Winnewisser, M.; Herbst, E.; De Lucia, F. C. The Millimeter- and Submillimeter-Wave Spectrum of trans-Ethyl Alcohol. J. Phys. Chem. Ref. Data 1995, 24, 1-32.

(26) Durig, J. R.; Bucy, W. E.; Wurrey, C. J.; Carreira, L. A. Raman spectra of gases. XVI. Torsional transitions in ethanol and ethanethiol. J. Phys. Chem. 1975, 79, 988-993.

(27) Kahn, K.; Bruice, T. C. Parameterization of OPLS-AA force field for the conformational analysis of macrocyclic polyketides. J. Comput. Chem. 2002, 23, 977-996.

(28) Kahn, K.; Bruice, T. C. Focal-Point Conformational Analysis of Ethanol, Propanol, and Isopropanol. ChemPhysChem 2005, 6, 487-495.

(29) Höfener, S.; Bischoff, F. A.; Glöß, A.; Klopper, W. Slater-type geminals in explicitly-correlated perturbation theory: application to $\mathrm{n}$ alkanols and analysis of errors and basis-set requirements. Phys. Chem. Chem. Phys. 2008, 10, 3390-3399.
(30) Kirschner, K. N.; Heiden, W.; Reith, D. Relative electronic and free energies of octane's unique conformations. Mol. Phys. 2017, 115, $1155-1165$.

(31) Gruzman, D.; Karton, A.; Martin, J. M. L. Performance of Ab Initio and Density Functional Methods for Conformational Equilibria of $\mathrm{CnH} 2 \mathrm{n}+2$ Alkane Isomers $(\mathrm{n}=4-8)$. J. Phys. Chem. A 2009, 113, 11974-11983.

(32) Venkateswarlu, P.; Gordy, W. Methyl Alcohol. II. Molecular Structure. J. Chem. Phys. 1955, 23, 1200-1202.

(33) Nishikawa, T. Fine Structure of $\mathrm{J}=1 \leftarrow 0$ Transition due to Internal Rotation in Methyl Alcohol. J. Phys. Soc. Jpn. 1956, 11, 781786.

(34) Kimura, K.; Kubo, M. Structures of Dimethyl Ether and Methyl Alcohol. J. Chem. Phys. 1959, 30, 151-158.

(35) Gerry, M. C.L.; Lees, R. M.; Winnewisser, G. The torsion-rotation microwave spectrum of $12 \mathrm{CH} 318 \mathrm{OH}$ and the structure of methanol. J. Mol. Spectrosc. 1976, 61, 231-242.

(36) Iijima, T. Zero-point average structure of methanol. J. Mol. Struct. 1989, 212, 137-141.

(37) Florian, J.; Leszczynski, J.; Johnson, B.; Goodman, L. Coupledcluster and density functional calculations of the molecular structure, infrared spectra, Raman spectra, and harmonic force constants for methanol. Mol. Phys. 1997, 91, 439-448.

(38) Culot, J. Fourth Austin Symposium on Gas Phase Molecular Structure, 1972.

(39) Demaison, J.; Herman, M.; Lievin, J. The equilibrium $\mathrm{OH}$ bond length. Int. Rev. Phys. Chem. 2007, 26, 391-420.

(40) Dobrowolski, J. C.; Ostrowski, S.; Kołos, R.; Jamróz, M. H. Armatrix IR spectra of 2-propanol and its OD, D7 and D8 isotopologues. Vib. Spectrosc. 2008, 48, 82-91.

(41) Inagaki, F.; Harada, I.; Shimanouchi, T. Far-infrared spectra and barriers to internal rotation of isopropyl alcohol and alkyl mercaptans. J. Mol. Spectrosc. 1973, 46, 381-396.

(42) Palke, W. E.; Kirtman, B. Ab initio versus molecular mechanics calculations for conformational energies of 2-propanol and cyclohexanol. J. Phys. Chem. 1988, 92, 3046-3048.

(43) Lathan, W. A.; Radom, L.; Hehre, W. J.; Pople, J. A. Molecular orbital theory of the electronic structure of organic compounds. XVIII. Conformations and stabilities of trisubstituted methanes. J. Am. Chem. Soc. 1973, 95, 699-703.

(44) Hirota, E.; Kawashima, Y. Internal Rotation of the Hydroxyl Group in Isopropanol and the Chirality of the Gauche Form: Fourier Transform Microwave Spectroscopy of (CH)32CHOD. J. Mol. Spectrosc. 2001, 207, 243-253.

(45) Maeda, A.; Medvedev, I. R.; De Lucia, F. C.; Herbst, E. The Millimeter- and Submillimeter-Wave Spectrum of Iso-Propanol [(CH)32CHOH]. Astrophys. J., Suppl. Ser. 2006, 166, 650.

(46) Abdurakhmanov, A. A.; Veliyulin, É. I.; Ragimova, R. A.; Imanov, L. M. The microwave spectrum of n-propanol. The gauche-gauche conformer. J. Struct. Chem. 1981, 22, 28-33.

(47) Lotta, T.; Murto, J.; Räsänen, M.; Aspiala, A. IR-induced rotamerization of 1-propanol in low-temperature matrices, and ab initio calculations. Chem. Phys. 1984, 86, 105-114.

(48) Jensen, F. Polarization consistent basis sets: Principles. J. Chem. Phys. 2001, 115, 9113-9125.

(49) Jensen, F. Erratum: "Polarization consistent basis sets: Principles" [J. Chem. Phys. 115, 9113 (2001)]. J. Chem. Phys. 2002, 116, 3502.

(50) Jensen, F. Polarization consistent basis sets. IV. The basis set convergence of equilibrium geometries, harmonic vibrational frequencies, and intensities. J. Chem. Phys. 2003, 118, 2459-2463.

(51) Kupka, T.; Lim, C. Polarization-Consistent versus CorrelationConsistent Basis Sets in Predicting Molecular and Spectroscopic Properties. J. Phys. Chem. A 2007, 111, 1927-1932.

(52) ElSohly, A. M.; Tschumper, G. S. Comparison of polarization consistent and correlation consistent basis sets for noncovalent interactions. Int. J. Quantum Chem. 2009, 109, 91-96.

(53) Feyereisen, M.; Fitzgerald, G.; Komornicki, A. Use of approximate integrals in ab initio theory. An application in MP2 energy calculations. Chem. Phys. Lett. 1993, 208, 359-363. 
(54) Vahtras, O.; Almlöf, J.; Feyereisen, M. W. Integral approximations for LCAO-SCF calculations. Chem. Phys. Lett. 1993, 213, 514-518.

(55) Ten-no, S.; Iwata, S. Three-center expansion of electron repulsion integrals with linear combination of atomic electron distributions. Chem. Phys. Lett. 1995, 240, 578-584.

(56) Møller, C.; Plesset, M. S. Note on an Approximation Treatment for Many-Electron Systems. Phys. Rev. 1934, 46, 618-622.

(57) Hehre, W. J.; Ditchfield, R.; Pople, J. A. Self-Consistent Molecular Orbital Methods. XII. Further Extensions of Gaussian-Type Basis Sets for Use in Molecular Orbital Studies of Organic Molecules. J. Chem. Phys. 1972, 56, 2257-2261.

(58) Francl, M. M.; Pietro, W. J.; Hehre, W. J.; Binkley, J. S.; Gordon, M. S.; DeFrees, D. J.; Pople, J. A. Self-consistent molecular orbital methods. XXIII. A polarization-type basis set for second-row elements. J. Chem. Phys. 1982, 77, 3654-3665.

(59) Dunning, T. H. Gaussian basis sets for use in correlated molecular calculations. I. The atoms boron through neon and hydrogen. J. Chem. Phys. 1989, 90, 1007-1023.

(60) Kendall, R. A.; Dunning, T. H.; Harrison, R. J. Electron affinities of the first-row atoms revisited. Systematic basis sets and wave functions. J. Chem. Phys. 1992, 96, 6796-6806.

(61) Weigend, F. A fully direct RI-HF algorithm: Implementation, optimised auxiliary basis sets, demonstration of accuracy and efficiency. Phys. Chem. Chem. Phys. 2002, 4, 4285-4291.

(62) Weigend, F.; Köhn, A.; Hättig, C. Efficient use of the correlation consistent basis sets in resolution of the identity MP2 calculations. J. Chem. Phys. 2002, 116, 3175-3183.

(63) Hättig, C. Optimization of auxiliary basis sets for RI-MP2 and RICC2 calculations: Core-valence and quintuple-[small zeta] basis sets for $\mathrm{H}$ to Ar and QZVPP basis sets for Li to Kr. Phys. Chem. Chem. Phys. 2005, 7, 59-66.

(64) Largent, R. J.; Polik, W. F.; Schmidt, J. R. Symmetrizer: Algorithmic determination of point groups in nearly symmetric molecules. J. Comput. Chem. 2012, 33, 1637-1642.

(65) Pitoňák, M.; Neogrády, P.; Černý, J.; Grimme, S.; Hobza, P. Scaled MP3 Non-Covalent Interaction Energies Agree Closely with Accurate $\operatorname{CCSD}(\mathrm{T})$ Benchmark Data. ChemPhysChem 2009, 10, 282289.

(66) Riley, K. E.; Řezáč, J.; Hobza, P. MP2.X: a generalized MP2.5 method that produces improved binding energies with smaller basis sets. Phys. Chem. Chem. Phys. 2011, 13, 21121-21125.

(67) Raghavachari, K.; Trucks, G. W.; Pople, J. A.; Head-Gordon, M. A fifth-order perturbation comparison of electron correlation theories. Chem. Phys. Lett. 1989, 157, 479-483.

(68) Rendell, A. P.; Lee, T. J. Coupled-cluster theory employing approximate integrals: An approach to avoid the input/output and storage bottlenecks. J. Chem. Phys. 1994, 101, 400-408.

(69) DePrince, A. E.; Sherrill, C. D. Accuracy and Efficiency of Coupled-Cluster Theory Using Density Fitting/Cholesky Decomposition, Frozen Natural Orbitals, and a t1-Transformed Hamiltonian. J. Chem. Theory Comput. 2013, 9, 2687-2696.

(70) Helgaker, T.; Klopper, W.; Koch, H.; Noga, J. Basis-set convergence of correlated calculations on water. J. Chem. Phys. 1997, 106, 9639-9646.

(71) Schmidt, M. W.; Baldridge, K. K.; Boatz, J. A.; Elbert, S. T.; Gordon, M. S.; Jensen, J. H.; Koseki, S.; Matsunaga, N.; Nguyen, K. A.; $\mathrm{Su}, \mathrm{S}$.; Windus, T. L.; Dupuis, M.; Montgomery, J. A. General atomic and molecular electronic structure system. J. Comput. Chem. 1993, 14, 1347-1363.

(72) Gordon, M. S.; Schmidt, M. W. In Theory and Applications of Computational Chesmistry: The First Forty Years; Gordon, M. S., Schmidt, M. W., Dykstra, C. E., Eds.; Elsevier: Amsterdam, Boston, 2005; pp 1167-1189.

(73) Turney, J. M.; et al. Psi4: an open-source ab initio electronic structure program. Wiley Interdiscip. Rev.: Comput. Mol. Sci. 2012, 2, $556-565$.

(74) Parrish, R. M.; et al. Psi4 1.1: An Open-Source Electronic Structure Program Emphasizing Automation, Advanced Libraries, and Interoperability. J. Chem. Theory Comput. 2017, 13, 3185-3197.
(75) Wassermann, T. N.; Zielke, P.; Lee, J. J.; Cézard, C.; Suhm, M. A. Structural Preferences, Argon Nanocoating, and Dimerization of nAlkanols As Revealed by OH Stretching Spectroscopy in Supersonic Jets. J. Phys. Chem. A 2007, 111, 7437-7448. 